\title{
laborhifórico
}

ISSN 2359-6910

https://revistas.ufrj.br/index.php/lh/

ARTIGO

Recebido em 20 de abril de 2019

Aprovado em 30 de maio de 2019

\section{O estudo da variação 'teu'/'seu': atuação do fator grau de parentesco}

The study of 'teu'/'seu' variation in Brazilian Portuguese:

effects of degree of relatedness

DOI: https://doi.org/10.24206/lh.v5iEspecial.25091

Rachel de Oliveira Pereira Lucena

Graduada em Letras pela Universidade Federal do Rio de Janeiro. Mestra e Doutora em Letras Vernáculas (Língua Portuguesa) pelo Programa de Pósgraduação em Letras Vernáculas da Universidade Federal do Rio de Janeiro.

E-mail: racheloplucena@gmail.com

ORCID: https://orcid.org/0000-0003-2089-7313 


\section{RESUMO}

O presente estudo objetiva analisar a variação existente entre as formas simples de pronomes possessivos de segunda pessoa do singular, isto é, teu/tua/seu/sua, diacronicamente, no português brasileiro, buscando explicar o que o motiva tal variação e observar em especial o comportamento do pronome seu. No presente estudo, será feito um recorte, sendo observados apenas os resultados referentes a um fator extralinguístico: o parentesco entre os missivistas. A análise quantitativa e qualitativa dos dados baseia-se nos pressupostos da sociolinguística variacionista (LABOV, 1994; WEINREICH; HERZOG; LABOV, 1968). Além disso, na análise dos pronomes possessivos serão observadas também as situações comunicativas em que os pronomes estão inseridos, observando as relações de poder na ótica da teoria de Poder e Solidariedade proposta por Brown e Gilman (1960). A hipótese norteadora do trabalho é a de que, nas relações mais íntimas, haveria o maior emprego de teu, enquanto nas relações em que há predominância de maior distanciamento entre os interactantes, haveria o emprego de seu. Tal hipótese se baseia nos estudos referentes à variação tu/você na posição de sujeito (SOUZA, 2012).

Palavras-chave: Pronomes possessivos. Variação. Diacronia. Sincronia. Teu/seu.

\section{ABSTRACT}

The present study aims to analyze the variation between the simple forms of second-person possessive pronouns of the singular, that is, teu/seu, diachronically, in Brazilian Portuguese, seeking to explain what motivates this variation and to observe in Particular the behavior of its pronoun. In the present study, a cut will be made, observing only the results referring to an extralinguistic factor: the kinship between the missivists. The quantitative and qualitative analysis of the data is based on the assumptions of the variationist Sociolinguistics (LABOV, 1994; WEINREICH; HERZOG; LABOV, 1968). In addition, in the analysis of possessive pronouns, the communicative situations in which the pronouns are inserted are also observed, observing the power relations in the perspective of the theory of power and solidarity proposed by Brown and Gilman (1960). The guiding hypothesis of the work is that, in the most intimate relationships, there would be the greatest employment of teu, while in the relationships in which there is a predominance of greater distance between the interactants, there 
would be the employment of $s e u$. This hypothesis is based on studies related to the variation $t u / v o c e$ in the subject position (SOUZA, 2012).

Keywords: Possessive pronouns. Variation. Diachronic. Synchronic. Teu/seu. 


\section{Introdução}

O presente trabalho propõe estudar a inserção do pronome possessivo seu como um pronome de segunda pessoa do singular, em cartas pessoais escritas por diferentes famílias, tanto ilustres como não ilustres, ao longo de 100 anos: de 1870 a 1970. Dessa forma, esta investigação é estruturada a partir da descrição e análise da variação entre duas estratégias de referência à segunda pessoa: teu e seu.

Portanto, o objetivo principal do estudo é analisar a variação entre os pronomes possessivos teu e seu, mostrando os contextos favorecedores de uma forma em detrimento da outra. Estas estratégias não serão analisadas apenas em termos descritivos, mas também à luz das teorias que discutem a questão da variação e mudança (WEINREICH; HERZOG; LABOV, 1968) e os fenômenos da cortesia (BROWN; GILMAN, 1960; BROWN; LEVINSON, 1987; VIDAL, 2002).

Com o presente estudo, pretende-se investigar a distribuição das formas possessivas nas missivas pessoais escritas ao longo de um século, observando o comportamento do pronome seu nesse período. Para mapear o uso dessas estratégias de tratamento até a década de 1970 do século XX na variedade brasileira do português, os dados serão analisados com base em algumas teorias sobre cortesia. A análise não será apenas quantitativa, mas será proposta uma leitura qualitativa e pormenorizada das ocorrências encontradas nas amostras.

A hipótese de estudo é a de que o possessivo seu/sua, por estar relacionado à forma você, teria o mesmo comportamento polifuncional do pronome pessoal correspondente. Isso quer dizer que seu assumiria diferentes valores ao longo do tempo.

\section{Pressupostos teóricos e metodológicos: a sociopragmática}

Nessa investigação, propõe-se estudar a relação entre os papéis sociais e as formas de tratamento empregadas nas missivas. O objetivo maior é mostrar a habilidade dos missivistas em relacionar o status e a sua representação linguística e não apenas documentar os tratamentos empregados nas cartas.

Segundo Vidal (2002, p. 13), a pragmática é uma disciplina que leva em consideração os fatores extralinguísticos que determinam o uso da linguagem, mais precisamente, todos os fatores aos quais não se pode fazer referência em um estudo puramente gramatical, como é o caso das noções de emissor, destinatário, intenção comunicativa, contexto verbal, situação ou conhecimento de mundo.

Preti (2000) correlaciona o conceito sociológico de papel e o conceito de status que, para o autor, referem-se à participação do homem na sociedade, em seu grupo social. $\mathrm{O}$ status pode ser definido como as diferentes posições assumidas por um indivíduo no grupo social, que tanto pode ser primário, 
ou seja, restrito à família, por exemplo, ou secundário, um grupo maior, como o Estado. Um mesmo indivíduo pertence a diferentes grupos sociais, portanto, ocupando diferentes posições sociais.

Em seu estudo, Preti também afirma que, dependendo do status que o indivíduo ocupa, ele se torna subordinado a certos comportamentos, que não se restringem apenas à sua postura ética, mas também a linguagem empregada por esta pessoa, já que é algo imprescindível à criação da imagem. Para o autor, as normas relacionadas ao status denominam-se papel social. Assim, pode-se afirmar com propriedade que o papel social indica o "caráter funcional do homem na sociedade" (PRETI, 2000, p. 86).

A variação linguística seria um traço fundamental que poderia caracterizar o status do falante ao exercer seu papel social. Nesse sentido, destaca-se, especificamente, o estudo das formas de tratamento, isto é, a maneira pela qual os interlocutores se tratam mutuamente e o que a escolha de uma forma em detrimento de outras disponíveis no repertório linguístico pode significar na interação verbal.

Com o intuito de se efetuar um estudo sobre as estratégias de referência à segunda pessoa do discurso, faz-se necessária uma averiguação cuidadosa das relações estabelecidas entre os participantes da situação comunicativa em questão. Para se entender essas relações, propõe-se a conjugação de algumas teorias de base pragmática, como a dicotomia "poder e solidariedade", de Brown e Gilman (1960) e a teoria da polidez, de Brown e Levinson (1987), aliando-as aos preceitos da sociolinguística variacionista (WEINREICH; HERZOG; LABOV, 1968).

Do estudo de Brown e Gilman, discute-se que a escolha das estratégias tratamentais referentes à segunda pessoa do discurso está regulamentada por duas relações, denominadas, poder e solidariedade, que estão presentes em todas as formas de interação entre interlocutores.

Desta maneira, o poder seria o domínio que uma pessoa exerce sobre outra em determinada situação comunicativa. Assim, para que o poder se estabeleça numa interação social, é necessário que haja pelo menos duas pessoas interagindo e que a relação estabelecida entre elas não seja simétrica. Conclui-se, então, que o poder encontra-se presente nas relações assimétricas, em que o conceito de hierarquia faz-se extremamente importante. Por outro lado, a solidariedade pressupõe um mesmo nível hierárquico decorrente de relações sociais simétricas. Tais relações estão ligadas, geralmente, às ideias de afinidade e afeto.

Da teoria da polidez, idealizada por Brown e Levinson (1987), leva-se em conta que na interação verbal os participantes possuem duas propriedades básicas que podem explicar seu comportamento a racionalidade e a imagem pública. No primeiro caso, considera-se que cada indivíduo possui um modo de raciocinar que pode ser definido de modo preciso e que o conduz aos meios necessários para chegar aos fins que deseja alcançar. No caso da segunda propriedade, defende-se que cada indivíduo constrói para si próprio, buscando manter o prestígio no meio social em que vive. A imagem pública possui duas vertentes: a face positiva e a negativa. A primeira consiste na personalidade (imagem) 
desejada pelos interactantes, ou seja, a maneira como os indivíduos desejam ser vistos pela sociedade. A face negativa, por outro lado, está relacionada ao território, ao direito de sofrer perturbação, à preservação pessoal, o que remete à liberdade de ação e liberdade para não sofrer imposição por parte dos outros.

Segundo os autores, qualquer ato de fala em si é considerado um ato de ameaça à face de nosso interlocutor, porque a imagem pública é vulnerável e a interação verbal nada mais é do que um esforço para preservá-la. Desta forma, as estratégias de polidez ou cortesia são empregadas para reforçar a imagem positiva do emissor e/ou do interlocutor, isto é, garantir a harmonia do processo interativo. Quando há uma estratégia que suaviza a imposição de um ato que ameace a face positiva do interlocutor, tem-se um caso de polidez positiva, e quando esse ato ameaça a face negativa, a estratégia utilizada é a polidez negativa.

Com base nos pressupostos sociolinguísticos, procura-se (i) pesquisar o grau de estabilidade ou mutabilidade do fenômeno variável, (ii) observar quais são as circunstâncias que favorecem ou não os usos alternativos e (iii) antever o comportamento sistemático e regular da variação. Para isso, é necessário na análise linguística, considerar a inter-relação entre os fatores internos e externos ao sistema.

\section{O corpus}

A amostra utilizada na presente pesquisa é composta por 363 cartas pessoais, escritas por pessoas oriundas do Rio de Janeiro ou que viveram no estado por algum tempo de suas vidas. Ressalta-se que as missivas foram escritas por indivíduos pertencentes a 12 grupos diferentes, sejam esses familiares ou não, entre os anos de 1857 a 1859.

A grande maioria das correspondências ${ }^{1}$ foi recolhida no Arquivo Nacional do Rio de Janeiro (Família Penna, Família Land Avelar, Família Pedreira Ferraz-Magalhães, Família Cupertino, Família Brandão), já as cartas da Família Cruz foram obtidas através do Departamento de Arquivo e Documentação (DAD) da Casa de Oswaldo Cruz (COC), também no Rio de Janeiro. As demais missivas foram retiradas do acervo do Projeto Labor Histórico (Família Lacerda, "Jayme e Maria, casal dos anos 30", Acervo Washington Luis, Amostra Robertina de Souza e Casal Ottoni). Importante mencionar que grande parte do material utilizado nesse estudo se encontra disponível no site do Projeto (http://www,letras.ufrj.br/laborhistorico).

${ }^{1}$ Cabe ressaltar que a Amostra Robertina de Souza é constituída por bilhetes e não cartas, porém, foram, neste estudo assumidos como correspondências. 
A denominação das diversas amostras foi realizada através do nome da família, uma vez que é justamente dessa maneira que o material é armazenado em arquivos públicos. No entanto, nesse corpus, há cartas de pessoas que não pertenciam a uma mesma família, como será ilustrado mais adiante. Cabe informar que, apesar de não ter sido controlado por um grupo de fatores específico, as amostras possuem certo grau de homogeneidade no que diz respeito à categoria social a que os escribas pertencem.

A tabela a seguir ilustra a organização da amostra utilizada para a realização desse estudo:

Tabela 1: Principais informações sobre o corpus adotado.

\begin{tabular}{|c|c|c|c|}
\hline Família/Grupo & $\begin{array}{c}\text { Período de escritura } \\
\text { das cartas }\end{array}$ & $\begin{array}{c}\text { Quantidade de } \\
\text { cartas }\end{array}$ & Subgênero das cartas \\
\hline $\begin{array}{c}\text { Cartas de Casimiro de } \\
\text { Abreu }\end{array}$ & $1857-1859$ & 11 & Pessoais \\
\hline $\begin{array}{c}\text { Acervo Cupertino do } \\
\text { Amaral }\end{array}$ & $1873-1895$ & 23 & $\begin{array}{c}\text { Pessoais, familiares e } \\
\text { amorosas }\end{array}$ \\
\hline $\begin{array}{c}\text { Cartas dos avós } \\
\text { Ottoni }\end{array}$ & $1879-1889$ & 41 & Pessoais \\
\hline $\begin{array}{c}\text { Acervo Família } \\
\text { Pedreira Ferraz- } \\
\text { Magalhães }\end{array}$ & $1884-1948$ & 33 & Pessoais \\
\hline $\begin{array}{c}\text { Acervo Oswaldo Cruz } \\
\text { Acervo Affonso Penna } \\
\text { Júnior }\end{array}$ & $1889-1915$ & 27 & Pessoais, familiares e \\
amorosas
\end{tabular}

\section{A distribuição das formas possessivas: parentesco}

Souza (2012) analisou 354 cartas redigidas por pessoas oriundas do Rio de Janeiro ou que viveram a maior parte da vida no estado. A autora delineou cronologicamente o comportamento linguístico da variação entre tu e você, na posição de sujeito, no período de 1870 a 1970. O gráfico de Souza (2012), reproduzido a seguir, ilustra tal mapeamento no decorrer de 100 anos: 
Figura 1: A variação entre tu/você, na posição de sujeito, ao longo de 100 anos.

Distribuição das formas você e tu ao longo do tempo

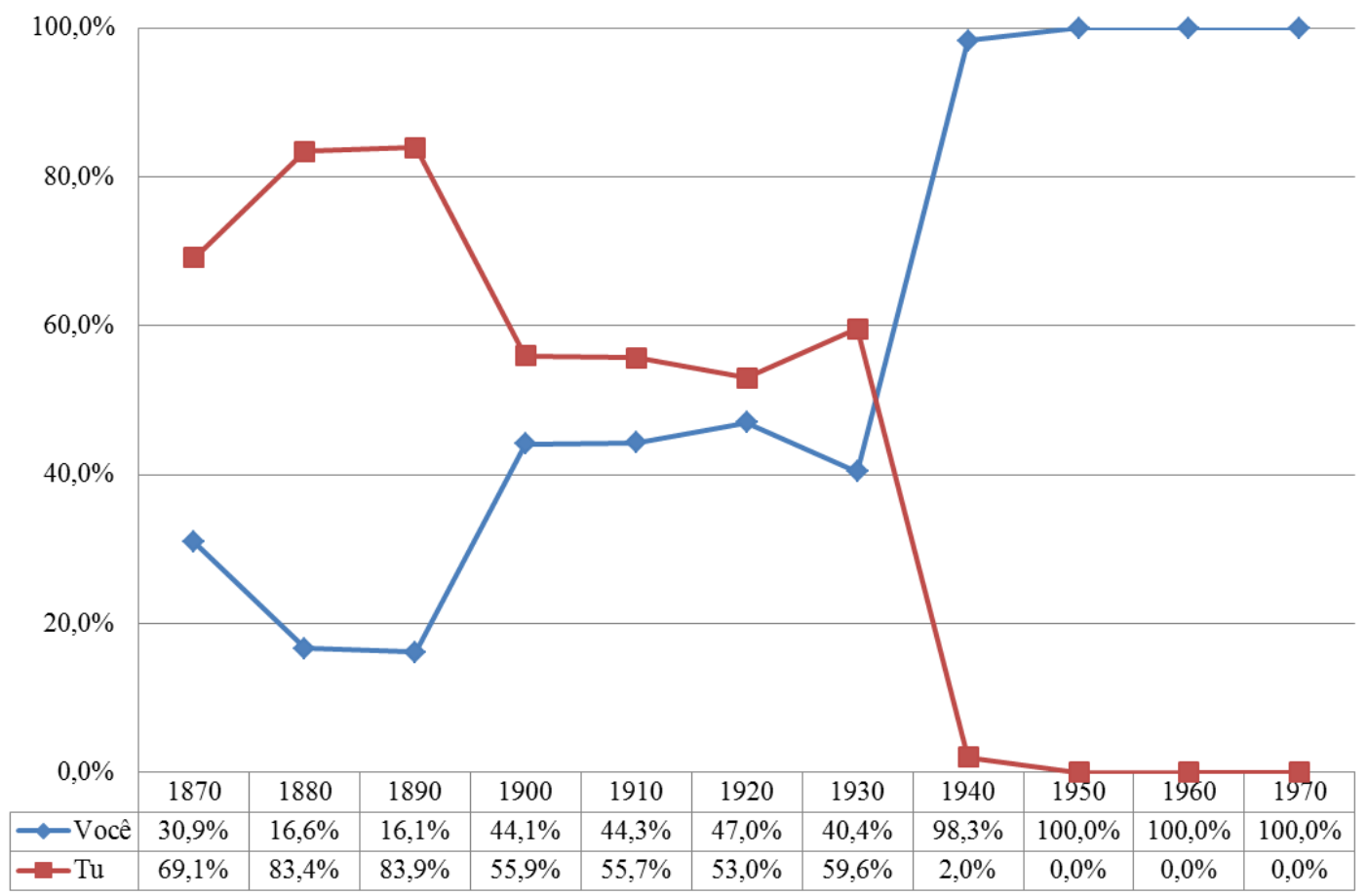

Fonte: Souza (2012, p. 90).

Com base nesses resultados, Souza (2012) traçou três períodos temporais para o processo de variação das formas pronominais de segunda pessoa na posição de sujeito. O primeiro corte temporal refere-se aos anos de 1870 a 1890, em que há maior utilização de $t u$ em detrimento de você. O estudo de Souza (2012) mostra, no entanto, que, nesse período, as duas estratégias não eram formas variantes no sentido estrito da palavra, já que não eram empregadas nos mesmos contextos discursivopragmáticos: $t u$ era mais empregado por homens e, principalmente, nas relações mais informais e próximas entre os interlocutores das missivas, ao passo que você era mais produtivo na escrita das mulheres, marcando deferência, distanciamento ou sendo uma forma de mitigar um ato de ameaça à face do interlocutor.

Assim, nesse segundo corte temporal, nota-se, a partir do gráfico de Souza (2012), a coexistência das duas estratégias com porcentagens mais equilibradas. Além disso, tu e você passam a dividir os mesmos espaços funcionais, caracterizando-se como variantes propriamente ditas. Isso se deve ao fato de a forma você ampliar seus contextos de uso, deixando de ser empregada apenas como uma forma de suavizar um ato ameaçador à face do interlocutor e perdendo o seu caráter de deferência e distanciamento social observado em fins do século XIX. Assim sendo, para o período de 1900 a 1930, Souza (2012) defende uma fase de variação entre $t u$ e você, fato que corrobora o estudo de Duarte (1993), em que esta autora afirma que é a partir de 1930 que você passa a ser realmente produtivo no português brasileiro. 
No último período temporal, isto é, aquele alocado entre as décadas de 1940 a 1970, percebe-se o emprego quase que categórico de você, em detrimento de $t u$, que cai em desuso no corpus. Souza (2012) observa que, nesse período, você passa a substituir o pronome $t u$ em todos os seus espaços funcionais, o que também dialoga com os resultados observados por Rumeu (2008), uma vez que a autora, ao realizar um estudo de longa duração com base em cartas pessoais de uma mesma família, também verificou que entre os anos de 1920 a 1945 a forma você mostra-se mais produtiva do que $t u$ na posição de sujeito. $\mathrm{O}$ comportamento linguístico identificado em fontes documentais distintas carta e peças teatrais - evidencia que os resultados não estão associados à natureza do gênero, mas sim, representa uma variação em curso da própria língua.

Assim sendo, assume-se, no presente estudo, que as formas variantes teu/seu, por hipótese, acompanham o comportamento das formas de tratamento na posição de sujeito e, por isso, foram realizadas rodadas parciais, de acordo com as fases temporais postuladas por Souza (2012).

Cabe ressaltar que a análise da variação dos pronomes possessivos de segunda pessoa baseou-se em uma amostra de 363 cartas pessoais, distribuídas pelo período temporal de 100 anos: entre 1870 e 1970. Nessas missivas foram encontradas 1.376 ocorrências de pronomes possessivos, com predomínio geral de teu sobre seu na totalidade da amostra. Foram 1041 dados de teu (76\%) e apenas 335 dados de seu/sua (24\%). No entanto, serão observados no presente artigo os resultados referentes ao grau de parentesco existente entre remetente e destinatário, observando, o grau de intimidade e as relações de poder estabelecidas entre os interactantes.

Parte-se da hipótese de que a maior proximidade entre os correspondentes, favoreceria o uso de teu, enquanto as relações em que há maior distanciamento entre os interlocutores, o seu seria mais frequente. Tal formulação estaria, em princípio, associada à correlação das formas possessivas aos seus respectivos paradigmas: de $t u$, no primeiro caso, e de você, no segundo. Leva-se assim em consideração não só as questões de Poder e Solidariedade propostas por Brown e Gilman (1960), mas também o que outros estudos apontaram sobre o emprego de formas de tratamento como estratégias de polidez que atuam para suavizar os atos de ameaça à face do interlocutor (BROWN; LEVINSON, 1997).

Souza (2008, p.124), por exemplo, ao realizar um estudo comparativo entre português e espanhol em peças teatrais, mostrou que pronomes de tratamento como Vossa Mercê e Vuestra Merced "configuravam distanciamento social entre os interlocutores". Além disso, nas relações assimétricas de superior-inferior, havia uma diversidade maior de formas empregadas para tratar o colocutor, do que em relações assimétricas de inferior-superior. Por fim, a autora declara que "apenas a partir das análises de cunho pragmático perceberam-se os distintos valores que cada forma de tratamento adquire, confirmando que o uso é que determina a regra." (SOUZA, 2008, p. 125). 
Nesse mesmo viés, Arduin (2005), ao estudar especificamente a variação entre as formas possessivas teu/seu, em corpus sincrônico de fala, mostrou que o pronome teu é mais produtivo em relações assimétricas de superior-inferior e também nas simétricas. Assim, na primeira situação, o uso se faz necessário para demonstrar poder e na segunda, solidariedade (BROWN; GILMAN, 1960). Por outro lado, o pronome possesivo seu é mais empregado nas relações assimétricas de inferior-superior, o que, de acordo com a autora, seria um uso "estilisticamente motivado" (ARDUIN, 2015, p.116).

Souza (2012), analisando a variação entre tu e você na posição de sujeito, cria um continuum que mostra o menor ou maior grau intimidade nas relações estabelecidas entre os missivistas. Assim, a pesquisadora identificou que as relações de parentesco em que havia menos intimidade entre remetentes e destinatário - família ampliada (tios, amigos, primos, avós) - favoreciam o emprego de você. As relações abarcadas no grupo família nuclear, ou seja, aquelas de consanguíneos advindos do casamento favoreceriam o emprego de $t u$ se fossem de inferior-superior (filho-pai) ou você se fossem de superior-inferior (mãe-filho). Já as relações entre casais (casados, noivos e namorados), por terem alto grau de intimidade, são desfavorecedoras do emprego de você.

Barcia (2006) analisou formas nominais e pronominais de tratamento ao interlocutor em cartas oitocentistas de leitores cariocas, mineiros e paulistas. Seus resultados apontaram para comportamento similar ao estudo de Souza (2012): quanto maior a relação de intimidade entre os missivistas, menor era o emprego de você. Assim, nas relações de cônjuges/casais, havia maior emprego de $t u$. Por outro lado, cartas entre amigos favoreceria o emprego de você. Por fim, em cartas trocadas entre outros familiares, mesmo com baixas frequências, a estratégia empregada era o vós e o Vossa Mercê. Nesse sentido, os resultados de Barcia (2006) parecem indicar que, nas cartas oitocentistas, a forma você era intermediária: não tão íntima quanto o $t u$, mas não tão distante quanto vós.

O grau de parentesco mostrou-se como grupo de fatores relevante nesse estudo, uma vez que foi selecionado em três das quatro rodadas: a rodada geral com todos os dados, a amostra relativa à fase 1 (1870-1899) e aquela referente à fase 2 (1900-1939). Os resultados, no que se refere a este grupo de fatores, serão apresentados através de tabelas separadas e não comparativas entre as quatro rodadas, pois, devido ao fato da amostra ser muito extensa e diversificada, há mais de 20 relações de parentesco estabelecidas entre remetente e destinatário. Separadamente, as tabelas serão mais elucidativas. A tabela a seguir elenca os resultados encontrados na rodada geral:

Tabela 2: O parentesco na rodada geral. Valor de aplicação: seu.

\begin{tabular}{|c|c|c|c|}
\hline Fatores & Aplicação/Total & $\%$ & PR \\
\hline Marido/Mulher & $12 / 30$ & $40 \%$ & 0.801 \\
\hline Amigos & $61 / 70$ & $87 \%$ & 0.820 \\
\hline Avô/Neto & $13 / 15$ & $87 \%$ & 0.814 \\
\hline $\begin{array}{c}\text { Namorado/Namorada } \\
\text { Noivo/Noiva }\end{array}$ & $65 / 527$ & $12 \%$ & 0.747 \\
\hline
\end{tabular}




\begin{tabular}{|c|c|c|c|}
\hline Pai/Filha & $7 / 112$ & $6 \%$ & 0.589 \\
\hline Tio/Sobrinho & $16 / 54$ & $30 \%$ & 0.368 \\
\hline Irmão/Irmão & $23 / 32$ & $72 \%$ & 0.153 \\
\hline Mãe/Filho & $46 / 101$ & $45 \%$ & 0.140 \\
\hline Pai/Filho & $27 / 72$ & $37 \%$ & 0.005 \\
\hline Filha/Pai & $1 / 15$ & $7 \%$ & 0.000 \\
\hline
\end{tabular}

$\mathrm{Na}$ análise geral dos dados, observou-se, a partir dos pesos relativos, o favorecimento de seu nas seguintes relações de parentesco: marido/mulher (0.801), amigos (0.820), avô/neto (0.814), namorado/namorada ou noivo/noiva (0.747) e pai/filha (0.589). Por outro lado, o favorecimento de teu se deu nas seguintes relações: tio/sobrinho (0.368), irmão/irmão (0.153), mãe/filho (0.140), pai/filho (0.005) e filha/pai (0.000).

A princípio tais resultados não confirmam as hipóteses iniciais postuladas sobre o uso da forma possessiva seu em contextos de maior distanciamento e respeito entre os interactantes, principalmente quando havia diferença de idade e de poder entre eles: relações entre filhos/filhas e pais ou sobrinhos aos tios, netos aos avós, entre outros. Da mesma forma, nas relações mais íntimas como entre cônjuges, amigos, haveria predomínio de teu.

Tal comportamento observado na rodada geral se deve provavelmente ao fato de que, como é proposto nesse estudo, os pronomes possessivos teu e seu teriam valores diferentes ao longo do tempo. Assim, ao defender que i) o possessivo seu foi assumindo valores sócio-pragmáticos distintos ao longo do tempo; ii) as relações de Poder e Solidariedade subjacentes às relações de parentesco se modificaram ao longo do período analisado; iii) os tipos de parentesco controlados nas cartas analisadas não foram sempre os mesmos nas fases postuladas; propõe-se, mais uma vez, uma análise pormenorizada por fases. A descrição dos resultados levará em conta ainda a associação do parentesco a outros aspectos extralinguísticos, tais como, a presença da consanguinidade que marcaria mais poder e a questão do gênero do remetente. Seguem, assim, os resultados relativos a cada fase:

\section{Parentesco na fase 1 (1870-1899)}

Tabela 3 - Relações de parentesco na fase 1 (1870-1899). Valor de aplicação seu.

\begin{tabular}{|c|c|c|c|}
\hline Parentesco & Aplicação/Total & $\%$ & PR \\
\hline Marido-Mulher & $3 / 20$ & $15 \%$ & 0.634 \\
\hline Pai-Filha & $7 / 103$ & $7 \%$ & 0.537 \\
\hline Mãe-Filho & $3 / 9$ & $33 \%$ & 0.144 \\
\hline Amigos & $1 / 10$ & $10 \%$ & 0.267 \\
\hline
\end{tabular}

No período referente a 1870 a 1899, as relações entre marido e mulher e pai e filha mostraram-se favorecedoras da forma possessiva seu/sua, ao passo que missivas trocadas entre amigos e mãe-filho 
desfavoreceram o uso do referido pronome possessivo. Ainda que o número de ocorrências não seja expressivo e que teu tenha sido o possessivo mais produtivo nessa fase, esses resultados confirmam algumas das hipóteses postuladas no que se refere, principalmente, ao emprego de teu nas relações mais simétricas (entre amigos) e assimétricas descendentes (mãe-filho). Com relação ao favorecimento de seu indicado pelo peso relativo, os resultados sinalizam alguns aspectos interessantes quanto ao caráter híbrido e polifuncional dessa variante possessiva no século XIX. Por um lado, tem-se o favorecimento de seu entre marido-mulher o que pode indicar que tal relação não era necessariamente "simétrica" no período em questão, por outro lado, o peso relativo de 0.537 para pai-filha (relação assimétrica descendente) dá indícios tímidos de seu atuando nos contextos típicos de teu.

Outro ponto merece destaque. É possível perceber que, das quatro relações estabelecidas, duas delas pressupõem figuras femininas como destinatários, o que poderia indicar que o emprego de seu era favorecido para a manutenção de certo respeito e distanciamento quando se escrevia para mulheres nesse período. A seguir seguem-se alguns exemplos do emprego de seu nas missivas:

(1) "Diga a sua mãe I que hei de escrever lhe I uma longa carta, e I lembre me a todos. I Até outra vez." (Família Cupertino do Amaral, relação marido/mulher, em 26 de fevereiro de 1886)

(2) "Agradeço-te desde já I a fineza e peço-te, meo caro I Antonico, que aceites um aper- I tado abraço do I Seo amigo velho e caro I Alberto Fiacho" (Família Cupertino do Amaral, relação entre amigos, em 5 de julho de 1895)

Em (1), percebe-se que, apesar de ser uma relação entre um casal de esposos, a relação entre Cupertino e sua esposa não é íntima e necessariamente solidária, uma vez que, na despedida, não há expressões que denotem saudade, apenas um "Até outra vez". Em (2), o trecho destacado mostra intimidade entre os interlocutores, através de expressões como "apertado abraço" ou o uso de apelidos, o que, aparentemente, leva a acreditar no estabelecimento de uma relação mais solidária. No entanto, a carta inteira é um pedido que Alberto quer que o amigo Cupertino realize, o que seria, nos termos de Brown e Levinson (1987), um ato que ameaça à face negativa do destinatário. Acredita-se, dessa forma, que o escriba se utiliza do possessivo seu como uma estratégia de polidez, entre outras, para reduzir o impacto negativo que seu pedido pode causar.

Aparentemente, no primeiro período, o uso de seu está relacionado à deferência e, principalmente, a um emprego diferenciado para as mulheres como uma estratégia que carrega traços de cortesia ou polidez. Para que se tenha um panorama mais completo dos diferentes graus de parentesco identificados nessa fase, apresenta-se, na tabela a seguir, o emprego de teu e seu em todas as relações observadas: 
Tabela 4 - Percentuais a depender das relações de parentesco encontradas na fase 1.

\begin{tabular}{|c|c|c|c|}
\hline \multicolumn{4}{|c|}{ Fase 1} \\
\hline Relação & & Teu & Seu \\
\hline \multirow{6}{*}{$\begin{array}{c}\text { Assimétrica } \\
\text { Descendente } \\
\text { (superior-inferior) }\end{array}$} & Avô-Neto & $\begin{array}{c}66 \\
100 \%\end{array}$ & - \\
\hline & Avô-Neta & $\begin{array}{c}11 \\
100 \%\end{array}$ & - \\
\hline & Pai-Filho & $\begin{array}{c}21 \\
100 \% \\
\end{array}$ & - \\
\hline & Pai-Filha & $\begin{array}{c}96 \\
93 \% \\
\end{array}$ & $\begin{array}{c}7 \\
7 \% \\
\end{array}$ \\
\hline & Mãe-Filho & $\begin{array}{c}6 \\
67 \% \\
\end{array}$ & $\begin{array}{c}3 \\
33 \% \\
\end{array}$ \\
\hline & Avó-Neto & - & $\begin{array}{c}5 \\
100 \%\end{array}$ \\
\hline \multirow{4}{*}{ "Simétrica" } & Marido-Esposa & $\begin{array}{c}17 \\
85 \% \\
\end{array}$ & $\begin{array}{c}3 \\
15 \%\end{array}$ \\
\hline & Amigo-Amigo & $\begin{array}{c}9 \\
90 \%\end{array}$ & $\begin{array}{c}1 \\
10 \%\end{array}$ \\
\hline & $\begin{array}{c}\text { Namorado/Namorada } \\
\text { Noivo/Noiva }\end{array}$ & $\begin{array}{c}138 \\
100 \% \\
\end{array}$ & - \\
\hline & Prima-Primo & - & $\begin{array}{c}14 \\
100 \%\end{array}$ \\
\hline
\end{tabular}

A tabela 4 mostra os resultados percentuais em todas as relações de parentesco estabelecidas na primeira fase. Diferentemente da tabela exclusiva com pesos relativos, é possível identificar na distribuição geral dos dados que, assim como as mulheres desse período favoreciam o uso de você, elas também empregavam mais seu/sua. Dos 26 dados encontrados em cartas femininas, 20 ocorrências são de seu, e em duas relações - avó-neto e prima-primo - há uso categórico dessa forma possessiva. Por outro lado, os homens são favorecedores de teu/tua, assim como no período em questão, os mesmos apresentavam índices majoritários de $t u$.

Nesse viés, é possível afirmar que a utilização das formas possessivas está intrinsecamente relacionada ao emprego que os missivistas faziam do pronome na posição de sujeito. Desse modo, percebe-se que os resultados encontrados nas variáveis gênero e parentesco na fase 1 (1870-1899) não estão em discordância. Observa-se, a partir de agora, a distribuição das formas possessivas no segundo período temporal: 


\section{Parentesco na fase $2(1900-1939)$}

A tabela a seguir aponta os resultados encontrados no segundo período temporal, compreendido entre os anos de 1900 a 1930. Como discutido anteriormente, nessa fase a variação entre teu e seu começa a se fazer notar com maior nitidez:

Tabela 5 - Relações de parentesco na fase 2 (1900-1939). Valor de aplicação: seu.

\begin{tabular}{|c|c|c|c|}
\hline Parentesco & Aplicação/Total & $\%$ & PR \\
\hline Mãe/Filho & $41 / 90$ & $46 \%$ & 0.994 \\
\hline Tio/Sobrinho & $16 / 54$ & $30 \%$ & 0.786 \\
\hline $\begin{array}{c}\text { Namorado/Namorada } \\
\text { Noivo/Noiva }\end{array}$ & $16 / 335$ & $5 \%$ & 0.406 \\
\hline Irmão/Irmão & $23 / 32$ & $72 \%$ & 0.335 \\
\hline Pai/Filho & $27 / 50$ & $54 \%$ & 0.001 \\
\hline Filha/Pai & $1 / 15$ & $7 \%$ & 0.019 \\
\hline
\end{tabular}

Os resultados identificados no período 2 (1900-1939) confirmam alguns dos indícios apontados na fase anterior: o comportamento híbrido de seu ora como estratégia de deferência ora como variante possessiva de segunda pessoa. $\mathrm{Na}$ fase 2 , a variante seu mostrou-se favorecedora em contextos típicos do teu-íntimo: relações assimétricas descendentes de mãe-filho com 0.994 e de tio-sobrinho com 0.786 de peso relativo. Entre pai-filho, no entanto, tal uso foi desfavorecido em termos do peso relativo, embora as frequências indiquem o contrário. Outros graus de parentesco apresentam resultados inusitados como será demonstrado na tabela a seguir com todas as ocorrências e percentuais encontrados, o que pode elucidar a análise:

Tabela 6 - Percentuais a depender das relações de parentesco encontradas na fase 2.

\begin{tabular}{|c|c|c|c|}
\hline \multicolumn{4}{|c|}{ Fase 2} \\
\hline Relação & & Teu & Seu \\
\hline \multirow{9}{*}{$\begin{array}{c}\text { Assimétrica } \\
\text { Descendente } \\
\text { (superior-inferior) }\end{array}$} & Pai-Filho & 23 & 27 \\
\hline & & $46 \%$ & $54 \%$ \\
\hline & Mãe-Filho & 49 & 41 \\
\hline & & $54 \%$ & $46 \%$ \\
\hline & Tio-Sobrinho & 38 & 16 \\
\hline & & $70 \%$ & $30 \%$ \\
\hline & Pai-Filha & $\begin{array}{c}9 \\
100 \%\end{array}$ & - \\
\hline & Avó-Neto & - & $\begin{array}{c}2 \\
100 \%\end{array}$ \\
\hline & Mãe-Filha & $\begin{array}{c}6 \\
100 \%\end{array}$ & - \\
\hline \multirow{3}{*}{$\begin{array}{c}\text { Assimétrica } \\
\text { Ascendente (inferior- } \\
\text { superior) }\end{array}$} & Filha-Pai & 14 & 1 \\
\hline & & $93 \%$ & $7 \%$ \\
\hline & Filho-Pai & - & $\begin{array}{c}10 \\
100 \%\end{array}$ \\
\hline
\end{tabular}




\begin{tabular}{|c|c|c|c|}
\hline & Filho-Mãe & - & 10 \\
& & & $100 \%$ \\
\hline \multirow{4}{*}{ Simétrica } & Namorado/Namorada & 319 & 16 \\
& Noivo/Noiva & $95 \%$ & $5 \%$ \\
\cline { 2 - 4 } & Noiva/Noivo & 145 & - \\
\cline { 2 - 4 } & Irmã-Irmã & $100 \%$ & 4 \\
\cline { 2 - 4 } & Irmão-Irmão & - & $100 \%$ \\
\cline { 2 - 4 } & & 9 & 23 \\
\cline { 2 - 4 } & Amantes & $28 \%$ & - \\
\cline { 2 - 4 } & & 27 & - \\
\cline { 2 - 4 } & Mulher-Marido & $100 \%$ & 7 \\
\cline { 2 - 4 } & Marido-Mulher & - & $100 \%$ \\
\hline
\end{tabular}

Os resultados encontrados na tabela 40 mostram que há um crescimento no emprego do pronome seu no segundo período temporal. Como mencionado anteriormente, seu se mostrou bastante presente nas relações assimétricas descendentes. Nota-se também que apesar de teu ainda ser mais produtivo nas cartas de mãe para filho, nessa relação, em específico, há um crescimento de 13\% de emprego do pronome possessivo seu, quando são comparados os resultados dos períodos temporais 1 e 2 . Apenas nas relações de pai-filha e mãe-filha teu aparece categoricamente. Por outro lado, na relação avó-neto, o uso de seu é exclusivo.

Assim, é possível inferir que, nas relações assimétricas descendentes, comparando os resultados encontrados nos períodos 1 e 2, seu passa a ser mais utilizado, uma vez que, no segundo período temporal, encontram-se 86 ocorrências de seu/sua, contra apenas 15 no primeiro corte temporal. Esses resultados mostram um crescimento de 560\% no emprego de seu nas cartas de relações assimétricas descendentes, o que parece ilustrar a propagação ainda tímida de seu como variante de teu em referência à segunda pessoa. Aparentemente, o pronome possessivo seu não estivesse mais tão relacionado à cortesia e distanciamento verificado no pronome seu/sua da fase 1, por isso, também o maior emprego dele de forma geral, principalmente nas relações assimétricas descendentes.

Nesse segundo período temporal, foram identificadas três relações de parentesco em que um remetente inferior escrevia a um superior, no entanto, todas elas são filhos ou filhas escrevendo ao seu pai ou mãe. Como este é um período em que a mudança na posição de sujeito ainda está em transição, o que se espera, a princípio, é uma relação menos solidária entre a filha e o pai, uma vez que, há uma hierarquização nessa relação. Assim, esperava-se encontrar mais formas relacionadas a você, como o 
pronome seu, que, nesse caso, explicitaria o respeito e a deferência que essa relação de parentesco exige no período em questão.

Dessa forma, foram encontradas 21 ocorrências do pronome seu e 14 de teu. Deve-se ressaltar, no entanto, que em duas relações houve uso categórico de seu: de filho para pai e de filho para mãe. A única relação em que teu prevalece é quando a filha escreve ao pai. Tais resultados parecem indicar que, na primeira metade do século XX, há um hibridismo e uma polifuncionalidade relacionada ao uso do pronome seu, que ora é mais íntimo, ora marca respeito e distanciamento.

Por fim, ainda no período 2, foram encontradas sete relações simétricas: namorado/noivonamorada/noiva, noiva-noivo, amantes, marido-mulher e missivas trocadas entre irmãos e irmãs. Nas cartas de irmão-irmão, há o maior emprego de seu, com $72 \%$ de frequência, enquanto na relação irmã-irmã há uso categórico do mesmo pronome. No entanto, cabe comentar as relações amorosas estabelecidas entre namorado/noivo-namorada/noiva, noiva-noivo, amantes e marido-mulher. Essas relações de parentesco, geralmente, são marcadas pela intimidade entre os interactantes, cujas cartas são de cunho mais íntimo. Assim, era esperado o emprego majoritário, senão categórico, de teu/tua, o que ocorreu em quase todas as relações. Entretanto, na relação marido-mulher ocorre o inverso: 100\% de emprego de seu. O trecho abaixo ilustra tal emprego:

(3) "Continue a escreval-as I assim, minha Negrinha, pois bem sabe que I Você é a unica, razão e o unico encanto da mi- | nha vida attribulada. Você e os [nossos] filhi- I nhos, parte da nossa alma! (...) Pela sua ultima carta, vejo que Dona | Angelina não pode tardar e urge [assentarem] I um plano que permitta sua completa sa- I hida da casa, afim de não crear embaraços. (...) Muitas e muitas saudades aos de casa. I Beijos aos filhinhos e guarde para I Você o coração [amantissimo] I do seu | Maridinho" (Família Penna, relação marido-mulher, em 16 de março de 1914)

É possível perceber, no exemplo (3), o emprego de apelidos como Negrinha e Maridinho, uso de palavras no diminutivo, como filhinhos, além de comentários sobre a vida de pessoas próximas, como Dona Angelina, o que configura que a relação estabelecida entre esse casal é íntima e solidária. $\mathrm{O}$ emprego categórico de seu em um tipo de relação com maior proximidade entre remetente e destinatário é um indício do espraiamento desse pronome no tratamento ao interlocutor para as relações simétricas. Observa-se agora os resultados encontrados no terceiro e último corte temporal. 


\section{Parentesco na fase 3 (1940-1979) e o espraiamento de seu nas relações simétricas: síntese dos resultados}

Na fase temporal 3, relacionada ao período de 1940-1979, não houve fatores extralinguísticos selecionados, logo, não há peso relativo para as relações de parentesco nesse interim. Entretanto, como a análise das relações de parentesco estão sendo analisadas também através da porcentagem, vale observar as ocorrências encontradas nesse lapso temporal, como ilustra a tabela a seguir:

Tabela 7 - Percentuais a depender das relações de parentesco encontradas na fase 3.

\begin{tabular}{|c|c|c|c|}
\hline \multicolumn{2}{|c|}{ Fase 3 } & Teu & Seu \\
\hline Relação & & 5 & 49 \\
& Namorado/Namorada & $91 \%$ \\
Simétrica & Noivo/Noiva & $9 \%$ & \\
& & & $\mathbf{5 8}$ \\
& Amigo-Amigo & & $100 \%$ \\
\cline { 2 - 4 } & & & \\
& & & \\
& & & \\
\end{tabular}

Embora não haja ocorrências de pronomes possessivos em relações assimétricas, o fato de seu aparecer com índices altos nas relações simétricas indica um emprego diferenciado desse pronome, se comparado aos dois primeiros lapsos temporais. Os resultados da fase 3 evidenciam claramente que o possessivo seu se consolida como uma forma variante de teu, uma vez que assumiu o contexto típico do possessivo original de segunda pessoa: relações simétricas e solidárias.

Embora não se tenha uma amostra completamente equilibrada em função dos problemas inerentes aos estudos de sociolinguística histórica, pode-se sintetizar no gráfico a seguir os resultados relativos ao grau de parentesco/relação simétrica-assimétrica. O gráfico evidencia um crescimento contínuo no emprego de seu ao longo dos períodos temporais controlados, em todos os tipos de relações: 
Figura 2 - Gráfico do crescimento de seu a depender do tipo de relação estabelecida.

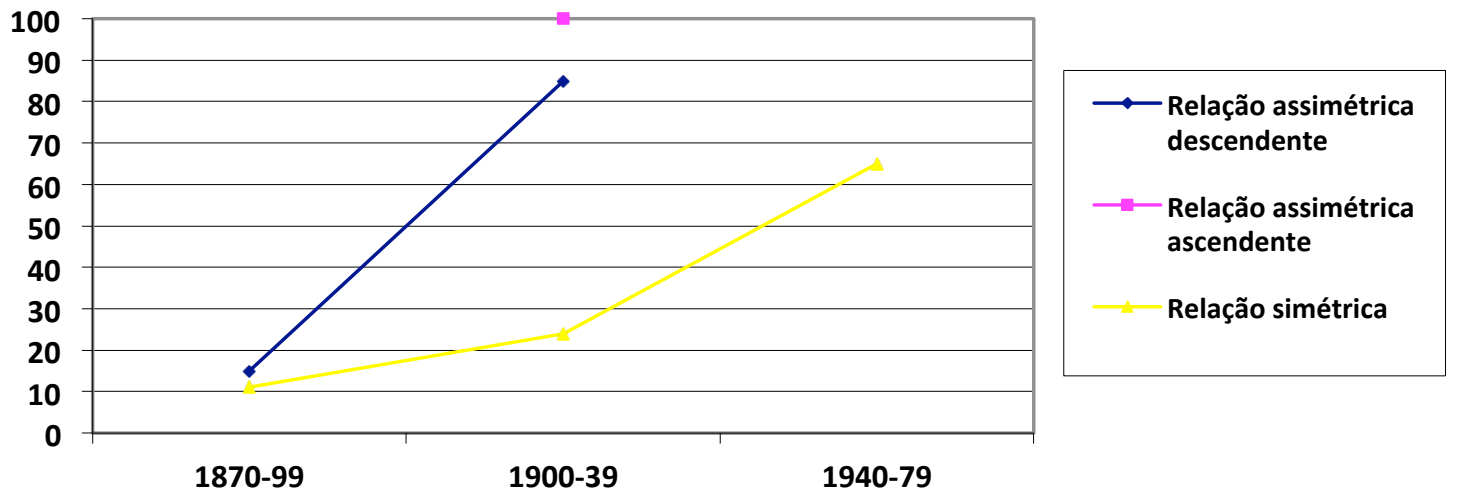

Nota-se o crescimento no emprego do uso do pronome seu nas relações assimétricas descendentes da fase 1 para a fase 2 e nas relações simétricas nas três fases. Assim, a relação assimétrica descendente equivale a $15 \%$ das ocorrências no período 1, passando a $85 \%$ de emprego de seu no período 2. Da mesma forma, na relação simétrica, observa-se o crescimento contínuo de seu: $11 \%$ na fase $1,24 \%$ na fase 2 e $65 \%$ na fase 3. Ressalta-se que cartas com relação assimétrica ascendente só foram identificadas no segundo período temporal.

Apesar de não terem sido encontradas as mesmas relações de parentesco ao longo de toda a amostra, é possível afirmar que os resultados indicam que, no início do século XIX, havia um predomínio de teu, mas, timidamente, seu vai aumentando e se difundindo nas diversas relações antes predominadas por $t e u$.

\section{Conclusão}

A distribuição global, na amostra, mostrou o predomínio de teu sobre seu. Assim sendo, das 1.376 ocorrências de pronomes possessivos encontradas, 76\% correspondiam a teu (1041 dados), enquanto $24 \%$ representavam seu (335 dados). Entretanto, uma investigação mais pormenorizada da variação das formas possessivas mostrou que essa distribuição não se deu de forma igualitária ao longo dos 100 anos de estudo: do século XIX até o final da década de 1930 há o maior emprego de teu, porém, a partir da década de 1940, há a maior utilização, muitas vezes categórica, de seu na amostra.

Não foi possível, ao longo dos 100 anos analisados, encontrar exatamente as mesmas relações de parentesco na amostra, mas os resultados apontaram para um crescimento tímido do pronome seu, tanto nas relações simétricas quanto assimétricas ascendentes e descendentes estabelecidas. 
Os resultados encontrados neste artigo apenas delineiam a variação entre as formas possessivas teu e seu em um recorte temporal de 100 anos, em que se verificou o crescimento tímido, porém contínuo do pronome seu como estratégia de referência à segunda pessoa. Há, sem sombra de dúvidas, ainda muitos questionamentos a serem desenvolvidos e respondidos sobre o tema. 


\section{Referências bibliográficas}

BARCIA, L.R.. As formas de tratamento em cartas de leitores oitocentistas: peculiaridades do gênero e reflexos da mudança pronominal. Dissertação (Mestrado em Letras Vernáculas Língua Portuguesa). Faculdade de Letras, Universidade Federal do Rio de Janeiro, Rio de Janeiro, 2006.

BROWN, R.; GILMAN, A. "The Pronouns of Power and Solidarity”. In: SEBEOK, T.A. Style in Language. Massachusetts: Ed. MIT Press, 1960. p. 253-276.

BROWN, P.; LEVINSON, S. Politeness: some universal in language usage. Cambridge: Cambridge University, 1987.

CONDE SILVESTRE. J. C. Sociolinguística histórica. Editorial Gredos, 2007.

HUERTA FLORES, N. Los Posesivos. In: COMPANY COMPANY, Concepción (Coord.). Sintaxis Histórica de la Lengua Española. Segunda parte: la frase nominal. México: Universidad Nacional Autónoma de México-Fondo de Cultura Económica, 2009. p. 611-757.

LABOV, W. Sociolinguistic Patterns. Pennsylvania: University of Pennsylvania Press, 1972.

LOPES, C. R. dos S. O quadro de pronomes pessoais: descompasso entre pesquisa e ensino. Matraga, v. 19, n. 30, 2012, p. $116-141$.

LOPES, C. R. dos S. Tradição e mudança no sistema de tratamento do português brasileiro: definindo perfis comportamentais no início do século XX. Alfa: Revista de Linguística, v. 55, 2011, p. 361-392. Disponível em: https://periodicos.fclar.unesp.br/alfa/article/view/4733.

MACHADO, A. C. M. As formas de tratamento no teatro brasileiro e português dos séculos XIX e XX. Tese (Letras Vernáculas). Faculdade de Letras, Universidade Federal do Rio de Janeiro, Rio de Janeiro, 2011.

MARCOTULIO, L. L. A preservação das faces e a construção da imagem no discurso político do marquês de Lavradio: as formas de tratamento como estratégias de atenuação da polidez linguística. Dissertação (Mestrado em Língua Portuguesa). Faculdade de Letras, Universidade Federal do Rio de Janeiro, Rio de Janeiro, 2008.

OLIVEIRA E SILVA, G. M. de. Estudo da regularidade na variação dos possessivos no Português do Rio de Janeiro. Tese (Doutorado em Linguística). Universidade Federal do Rio de Janeiro, Rio de Janeiro, 1982.

RUMEU, M. C. de B. A implementação do "Você" no português brasileiro oitocentista e novecentista: um estudo de painel. Tese (Doutorado em Língua Portuguesa). Faculdade de Letras, Universidade Federal do Rio de Janeiro, Rio de Janeiro, 2008.

RUMEU, M. C. de B. Língua e Sociedade: a história do pronome "Você" no português brasileiro. Rio de Janeiro: Ítaca, 2013. 
SOUZA, J. P. F. Mapeando a entrada do você no quadro pronominal: análise de cartas familiares dos séculos XIX-XX. Dissertação (Mestrado em Língua Portuguesa). Faculdade de Letras, Universidade Federal do Rio de Janeiro, Rio de Janeiro, 2012.

WEINREICH, U.; HERZOG, M.; LABOV, W. Fundamentos empíricos para uma teoria da mudança linguística. São Paulo: Parábola, 2006 [1968].

VIDAL, M. Introducción a la pragmática. Barcelona: Ariel, 2002. 